\title{
Scientific Approaching in Development Policy of Elementary School Curriculum 2013
}

\author{
Alif Mudiono \\ State Universitas of Malang, Indonesia \\ alifmudiono@gmail.com
}

\begin{abstract}
In this time scientific approaching in elementary school curriculum 2013 becomes discussion substance which is stunning of educators. Application of scientific approaching implemented through observation process, asking, collecting the information, thought, and communication. Oriented thematic learning in elementary school using scientific approaching is not only esteemed from the result of study that student achieved on integrative. However, learning is more emphesizing to searching science process competence and involving the students in learning process actively. In this case, teacher contributed as a facilitator for helping the students in constructing concept, principle, and stages for identification although finding, and problem solving. Likewise, teacher in implementation of learning using this approaching is not getting loose from policy in curriculum. In this study describes about: (1) learning through scientific approaching; (2) curriculum position in education and learning; and (3) assessment system in elementary school Curriculum 2013.
\end{abstract}

Keywords: scientific approaching, development policy, elementary school, curriculum 2013

\section{INTRODUCTION}

Oriented thematic learning implemented using scientific approaching designed to make students actively to construct the concept, principle through observation stages, problem formulating, submit or formulate the hypothesis, collecting data in various techniques, data analysis, made conclusion, and communicating the concept or found the principle. Scientific approaching is intended for providing comprehension to the students in knowing, understanding several of material using scientific approaching, that information can be from everywhere, it is not reckon on same direction information from teacher. Therefore, learning condition expected to create for supporting the student in searching of knowing from various resources through observation, and it is not giving explanation.

Application of scientific approaching learning involves competence process such as observation, classification, measurement, prediction, explanation, and conclusion. In implement that process, helping of teacher is needed. However, that helping must be decreased when the students have a higher level class or higher age. Besides, it is emphasizing in process of looking for knowledge than transfer of knowledge, students viewed as study subject that need to involve actively in learning process, teacher is only facilitator to guide and coordinate of learning activities.

Scientists convince that through the scientific approaching, it can make student more active in construct of knowledge and their competence, but it is also to encourage the students for implementing of investigating to find the facts from a phenomena or events. So, the students directed to find by themselves several of facts, construct the concept, and new values that needed for their life. The focus of learning process directed to develop of students skills in processing of knowledge, finding and developing the fact their self, concept, and the values needed.

\section{STEPS OF SCIENTIFIC APPROACHING}

In regulation of education and culture ministry No.18 A 2013 Enclosure IV about General Reference Learning stated that learning process consist of five main experience learning, those are: observation, asking, collecting information or experiment, association and communicating. The explanations are follows:

Observation learning activity implemented in observation process are reading, listening, observing, and seeing without tools. Competences that developed are training truth, precision, finding information. Observation method gives a priority of meaningful learning. This method has certain level best, like present an object media manifestly, the students are happy and challenged and easy to do it. The observation activity of learning usually needs long time preparation and properly constructed, need more cost and energy, and if it is not restrained, it will blur of meaning and purpose of study. Observation method is utilized to full of student curiosity.

So that, learning process has a high meaning. By observation method the students can find the fact that there are relationships between analyzed object with learning material that used by the teacher. Observation activity in learning implemented by this several steps. Determining what object that will be observed, make manual observation concerning space of object that will be observed, determining what data need to observe clearly, primer or secondary.

Determining where the place of object that will be observed. Determining how observation will be done for collecting the data clearly so that easy and smooth activity. Determining of the way and implement a note of observation result. Such as, using note book, camera, tape recorder, video recorder, and so on. Observation practice in learning will be effective if the students and teacher complete their selves with note equipments and others, such as: (1) tape recorder to record the conversation; (2) camera, to record the object or audio visual recorded; and (3) other requirement equipment.

Asking learning activity implemented in a way: ask the question about the information that is not understanding from the observation objector question for getting additional information about object observation (began from the question factual until the hypothesis question). Competence that developed is 
developing creativity, curiosity, competence to formulate the question for creating the critical thought that need for smart life and learning every time. The question is not only in question of sentence, but it can be question form, both of question need verbal response.

Collecting information/experiment the learning activities are: doing experiment, reading other references beside the text book, observing the object/events/activity, and interviewing the resource person. Competence that developed in collecting information /experiment process is developing precious attitude, honest, respectful, appreciate the other statement, communication competence, applying the competence to collect the information through various ways that be learned, developing study habit and along the time. To get real and authentic of study result, the students must try or do experiment.

The students must own the skill process for developing of science about the nature, and can use science method and have science attitude to solve the problems that they faced every day. So that the process of experiment is going fast: (1) teacher must formulate purpose of experiment that will be implemented by student; (2) teacher and students prepare the equipment that will be used; (3) need to calculate place and time; (4) teacher supplies paper work for direction of student activity; (5) teacher discusses the problem that will be become the experiment; (6) divide the paper work to the students; (7) the students implement the experiment in guiding of teacher; and (8) teacher collecting the work result of students and evolution them, if it needs to discuss in classically.

Associating /process information learning activity that implemented in associating/ process information is processing the information that was collecting from the result of activity collecting /experiment or the result of observation activity and collecting information activity. Information process collected from additional wide character and deep until information process to find the solution character from various resource that have different statement until the opposite statement. Competence that developed in associating process/ information process is developing honest attitude, precious discipline, rule arrangement, hard working, competence to apply procedure and thought competence inductive and deductive in conclusion.

In associating/ information process activity found reasoning activity. Technical term of "thinking" in learning process frame with scientific approaching found in Curriculum 2013 for describing that teacher and student indicate of active agent. The emphasizing point is in many kinds of case and the situation of student must be more active than teacher. Reasoning is logic thought process and systematic of empiric facts that can be observed to get the conclusion in knowledge form. Reasoning meant indicating scientific reasoning. Although reasoning of non Scientifics not always utilized. Technical term of reasoning here indicates of comparison from associating, it is not indicate translated from reasoning. Although, it is meant a reason or reasoning. Therefore, technical term of reasoning activity in learning context of curriculum 2013 with scientific approaching refer to association learning theory or associative learning.

Technical term of association in learning refer to competence of grouping various ideas and association various events after that enter them become part of memory. How to apply in development of learning activity process for increasing reasoning energy of students can be implemented in these ways. Teacher arranges learning material in ready form appropriate with curriculum demand. Teacher does not implement of communicative method or lecture method. Main job of the teacher is giving short instruction in clear explanation with example that are doing by themselves or simulation ways. Learning material arranged step by step/hierarchically. Began from simple (low regulation) until the complex (high regulation). Learning activity oriented to the result that can be measured and observed. Every mistake has to be corrected or repaired. Need to implement of repetition and exercise so that behavior which expected can become the habit or common. Evaluation or assessment based on the real or authentic behavior. Teacher writes all of student's progression, if it needs to give to the student remedy learning.

Communication learning activity is to convey the result of observation, the conclusion based on the result of oral analysis, written, or the other media. Te competence that developed in communication stages are developing honest behavior, precious, tolerant, thought systematic competence, express the statement shortly and clearly, and developing language competence well and correctly. In communication activity can implement collaborating learning. Collaborative learning indicates a personal philosophy, more than learning technique in classroom of school.

The essence of collaboration is interaction philosophy and human life style that occupy and meaning of cooperative as interaction stucture that designed well and designed for making easy of collective effort to reach the purpose together. In collaborative learning the authority of teacher and teacher function are directive or learning manager. The other ways, the students are more active. If collaborative learning positioned as a personal philosophy, it touches about identity of students especially if they related and interacted with other or teacher. In collaborative situation, students interacted by empathy, appreciate each other, and accept the lack or the excess each other. In that ways, it will grow the sense of security so that the student possible faces various changes and learning demand together.

Application of scientific approaching in mathematic learning, so example in material of numeral pattern are follow: observing, accurate daily problem that have related with numeral pattern, like determining next pattern from suite of ball, chair, stick, or other visual pattern. Asking about the usage of pattern in daily life. Asking about numeral pattern concept. Example, how to apply, predict the events, next events based on the observed pattern? Collecting the information, digging the information about the usage of pattern in daily life. Digging the information 
about numeral pattern, geometry pattern based on the data that was prepared. Digging the information of rule from numeral sequence and geometry sequence based on the data that was prepared in reasoning or association.

\section{POSITION OF CURRICULUM IN EDUCATION AND LEARNING}

Curriculum has strategic position in learning. Start from this case that curriculum development must notice the reason or strong base for producing education program and learning in the school. Based on it, education program was produced; it will produce human skill appropriate with the truth of humanity, fine for the present life or commemorate the next future life. By using precise and strong base, curriculum development is not only needed by curriculum compiler in macro level. However, it needed comprehension and became determining material by developers curriculum in operational level (education unit) that are: teacher, head master, education supervisor, education council or education committee and the other stacked holder.

The chosen base for becoming the base of developing curriculum depended on or influenced by culture, sight of life, political policy that used by a country in the place of curriculum developed. Commonly, formulation base curriculum policy includes philosophy base, juridical, physiological, sociological, and science and technology base. In this case, education philosophy base indicates base of frame that is very fundamental for education system and teachers. Philosophy frame gives a picture about the way of teacher view toward education itself (including themselves, curriculum, education purposes, and content of education), the students include learning process.

Philosophy frame expected to be a frame of teacher thought or teacher mind set in conducting of learning. The pedagogical reason provides some conceptual comprehension and learning occurred in various environment, including take care of children pattern, learning model, learning method, and learning technique, media usage, and learning resources, design steps of learning, and educate assessment. The relationship of this philosophy, Sukmadinata (in Hamid: 6.29) education philosophy basically indicates of application from philosophy thought for solving the education problem. Some philosophy views are many constituting and curriculum implement explain are follows.

First, positivism or empiricism constitutes development of science, especially natural science. Curriculum development of academic subject or curriculum science based, skills and values to young generation. Education is more emphasizing to mastery of material that took from science disciplines. Curriculum developer arranges the content of curriculum choose and take the materials from various science discipline, balanced with student development stage.

Second, pragmatism continues education concept that gives position to the student as a subject and has the bigger role in study (student centered). According to this philosophy, the students have thought competence and problem solving. Education is not heir and conveys the knowledge, skills, and values to the students, but it is dialog process for doing reconstruction of knowledge.

Third, existentialism is more emphasizing individual and social development. Education directed to appear of individual and social change. Education indicates of effort to do transformation change or either development of student selves as the society or in society itself. Teaching is more emphasizing to solve the problem either social problem or the student problem. The student learns in group to solve the problem.

National education philosophy base, national education objective in Indonesia sourced of view and ways of living of Indonesian, it is Pancasila. This case meant that education in Indonesia must bring the student in order to become the student that implement of the Pancasila. The other words, base and direction are created by education in Indonesia is appropriate of pancasila philosophy content itself. Laws No.20 in 2003 about national education system formulates, national education based on Pancasila and basic laws of Indonesia in 1945 (section 2). National education has function to develop skills and create the character and status of civilization to educate the notion life, aimed to develop of student potential in order to become human faithful and pious to the God, good character, healthy, bookish, capable, creative, autonomous, and becomes democratic civil and responsibility.

In relationship of implementation curriculum 2013 in elementary school level and junior level based by philosophy thought. Philosophy aspects become the basic of implementation of curriculum 2013 are follows: (1) education rooted to notion of culture, the present life, and build base of life in the future; (2) education is heir of process and developing culture; (3) education provides basic for the student to involve in constructing the present of life; (4) education develops various potential of the student; (5) education is construction process of student character; and (6) education positions the students as a subject of study.

By learning documents has related of curriculum 2013 implementation, so application of philosophy base can be seen in four case, curriculum idea or concept, curriculum content, learning process, and assessment process. Seen from idea or concept, application of philosophy base in curriculum 2013 reflected the usage of model competency based curriculum, standard based, rooted to Indonesia culture, prepare for the present life and the future life, emphesizing to the balance between soft skills and hard skills, and school is not separated with society. Seen the content of curriculum, application of philosophy base in curriculum 2013 reflected with core competency (Kompetensi Inti / KI) (is KI-1 spiritual behavior, KI-2 social behavior, KI-3 knowledge, and $\mathrm{KI}-4 /$ skills), basic competence of subject, a simple content, competency is more increasing, and proper with the student environment. 
Seen from learning process, application of philosophy base in curriculum 2013 reflected with direct learning concept and indirect, emphasizing to application, related with the life, developing the knowledge, observation, asking, collecting information, processing / associating, and communicating of finding and emphasizing to critical thought competence, creative, and productive, and developing learning competence. Seen from the assessment process of learning result, philosophy base in curriculum 2013 reflected to the emphasizing of thought competence and emphasizing to behavior and attitude, but the science aspect is still respected (Hamid, 2015). Based on it, implementation of Curriculum 2013 in elementary school has still problems which need to solve through the policy, they are: usage of thematic book that have different content with student development condition and around the region, usage of scientific approaching is too forced and assessment system is still difficult.

Juridical base in curriculum development context in Indonesia refer to Laws No. 20 in 2013 about National Education System in developing process, processing and implementation of education. Curriculum must be developed refer to national standard and directed for creating national education objective and in frame of Indonesia country. Furthermore, set in content of curriculum has to appear in curriculum in every education unit.

Especially implementation of Curriculum 2013, beside the laws above, the other legal aspect to be base in developing curriculum is Government Regulation Number 32 in 2013 about Change of Government Regulation Number 19 in 2015 about Standard National Education, particularly it has related with standard of graduate competence, standard of content, standard of process, and standard of assessment. Four of this standards are found in Regulation of Ministry Education and Culture Number 54 in 2013 about Standard Graduate Competence, Regulation of Ministry Education and Culture Number 65 in 2013 about Standard of Process, Number 66 in 2013 about Standard of Assessment, and Standard of Content for Elementary Education found in Regulation of Ministry Education and Culture Number 67 in 2013 about Basic Frame and Structure of Elementary School / Islamic Primary School Curriculum and Regulation of Ministry Education and Culture Number 68 in 2013 about Basic Frame and Structure of Junior High School/Islamic Junior High School. Meanwhile, Regulation of Application in Implementation Curriculum 2013 it found in Regulation of Ministry Education and Culture Number 81A in 2013 About implementation of Curriculum (Hamid, 2015).

Physiology base in developing curriculum process expected to implement relevant by student, either balancing of material that have to give to the student or from side of delivery and learning process and balancing from the other elements. Two branch of physiology science has related in developing curriculum process is physiology development and physiology learning. Physiology development is science that learning about behavior of individual relationship with their growth. In physiology development investigated about the essence of development, development stage, development aspects, task of individual development, and the other that have related with individual growth, all can be determining material and constitute curriculum development. Physiology learning is investigating about the essence of study and learning theory, and various aspect of the individual behavior in the study, all can be determining material that constitute of curriculum development.

Behavior of characteristic every individual in growth level is investigating that found in branch of physiology development. Therefore, in curriculum development related with education program for importance of student, so that, physiology base must be become a basic of developing curriculum process. Developing experienced by student commonly to get through learning process. Teacher as educator must try the way or method better for implementing learning process to obtain the result optimally; in this case learning process needed a deepest thought with physiology learning notice.

Physiology development needed determining content of curriculum that provided/learned the student, depth level and width material, difficulty level and expediency, and utilizing that balanced of step and development task of student. Physiology learning provides contribution toward curriculum development especially related how curriculum give to the student and how the student have to learn, it meant to relate with the strategy of curriculum implementation.

\section{PHYSICOLOGY AND CURRICULUM DEVELOPMENT}

Since the child was born, they were shown the different unique one with the other, like crying and body movement. This case describes that child has potential to be growth. In physiology development found many science statements related with individual growth in every development phase. Views of child as unique beings has influenced toward education curriculum development. Every child indicates personal individual, own their differences and similarity.

Implication of this case toward the curriculum development is: (1) every child gave opportunity for developing appropriate with their talent, interest, and need; (2) provided learning in common (core program) that must be learned the student in the school, provided a choice learning appropriate their talent and their interest; (3) except curriculum provides learning material in vocational material also provides learning material in academic; and (4) curriculum brings the aim that content of knowledge, value/behavior, and skill describing all of entire personal external and internal.

The other implication of knowledge about child as the student toward learning process (actual curriculum) can explains: (1) learning purposes formulated operationally centered to change of the students behavior; (2) substance/material learning provided has to appropriate of requirement, interest, and the attention of child, the substance is easy to 
accept by child; (3) learning strategy that used has to appropriate with stage of child growth; (4) media that used is always interesting the student and interest of child; and (5) oriented evaluation system in unity is comprehensive and connected from one stage to the next stage and implemented continuously.

\section{Learning and Curriculum Physiology}

Learning physiology indicates a branch of science that explains how the individual learning. Learning can be meant as change of behavior occurred through the experience. According to Indonesia Language Dictionary, learning comes from word "learn" that mean a direction gives to someone in order to known /followed. All of behavior change occurred because of experience process can be categorized as learning behavior. The change happened instinctly and it is accidently but it is not included of learning.

\section{Energy Discipline Theory / Mental Discipline (Faculty Theory)}

According this theory, since the child was born owned a potential or certain energy (faculties) each has a certain function, like remember potential / energy, thought energy, energy of express the statement, observation energy, problem solving energy, and the equivalent. The potentials can be trained and can be functioned optimally, the child of thought energy often trained with counted learning, example, remember energy trained with memorizing something. Energy has trained transferred in other form. This transfer implemented through the drill, because of it the meaning of learning in this context trains the student in those energy, commonly learning ways through the memorizing and exercising.

\section{Behaviorism}

In this behaviorism found 3 theories that covering connectionism/association, condition theory, and reinforcement theory. Behaviorism appears from the sight that individual does not bring the congenital potency. Developing of an individual influenced by environment (family, education institution, and society). Behaviorism supposed that development of individual is not appearing from mentality, developing is only connected in reality that can be seen and observed.

According this theory, life is obedient to the law of stimulus - respond or action and reaction. According this theory, basically learning is relationship of respond - stimulus. Learning is effort for creating relation stimulus-respond optimally. The scientist is Edward L. Thorndike emerge 3 theory of learning those are law of readiness, law of exercise, and law of effect. According law of readiness relationship between stimulus and respond will be created if there was readiness of individual nerve system. Law of exercise or repetition stimulus and respond will be created if it often exercised or repeated. Law of effect states that relationship between stimulus and respond will be occurred if there was the effect of happiness.

\section{Cognitive Gestalt Field}

According this theory, whole is more meaningful than parts, whole is not collection of parts. Human reputed as a being that is doing feedback relation with environment entirely, this relation made by stimulus and respond. Stimulus selected following the purposes, then, individual implements of interaction continuously, so that, it was happened a learning process. In this case, teacher has role as the instructor not source of information that reveal in connectionism views, the student has role in learning process, direct learning based on the experience, it is interaction of activity between individual and the environment. Learning according this theory is not memorizing but solving the problem, and learning method that used is scientific method using the way the student expected in a problem that the problem can be solve by the student selves. Finally, the student can be guided for taking a conclusion together from what they learned.

Sociological base directs an explanation about curriculum that has related with society and culture aspect. As a design or program, curriculum is determining of implementation and education result. Education will prepare the student as the young generation for living in environment of society. Therefore, education must provide of knowledge provision, skills, and values for living, work, and reach next developing in society. Developing curriculum program must be based and directed to society life with all of characteristics and culture wealth.

Curriculum as education program has to get to answer the challenge and society demand, it is not only side of content program but it is also from approaching side of implementing strategy. Therefore, teacher as the implementer of curriculum demanded to have sensitivity to prevent developing of society, so that, what the delivery to the student is relevant and benifical for their life in society.

Basically, education is part of culture, moreover, it can be stated that education is a process of cultural for increasing the human status and level. Cultural process cannot take itself, but it must be interaction with the other and their environment (Hasan, 2005). Science and technology base directly becomes the content / education material, and indirectly provides the assignment to the teacher, give the provision to the society competence to solve the problem in education. The implication of knowing technology, example, computer needs to introduce in elementary school.

\section{Integrated Thematic Learning in Curriculum 2013} Integrated thematic learning applied in elementary school in curriculum 2013 based on regulation of ministry education and culture number 65 in 2013 about standard of elementary education process and junior states, appropriate with standard of graduate competence and standard of content, so, learning principles used from partial learning to integrated learning. Implementation of curriculum 2013 in Elementary School/Islamic Primary School has 
done through the learning of integrated thematic approaching from level class I to level class VI.

1. Integrated thematic learning approaching provided elementary school start from class I to class VI.

2. The approaching used for integrating basic competence from various subject are follows; intradicipliner, interdicipliner, multidicipliner, and transdicipliner. Intradicipliner is integration of behavior dimension, knowledge and skills entirely in every subject that integrated through the theme. Interdicipliner is combining the basic competences some a subject in order to related one to the other, like in science subject and social subject that integrated to various the other subject. That case described in elementary school curriculum structure for class I - III there is no science and social subject but the capacity of science and social integrated to the other subject especially Indonesia language. Multidicipliner is approaching without combining basic competence alone. The image is science and social stand alone in class IV - VI. Transdicipliner is approaching in determining a theme that has related with various competences from the subject with the problem surrounding them.

3. Integrated thematic learning arranged based on combination of various integration process and various competence.

4. Integrated thematic learning enriched with placing Indonesia language subject as drag/tools/media the other subject.

5. The assessment has done referring to indicator each basic competence from each the subject.

Integrated thematic learning presents the concepts from various subjects that found in Basic Competence KKI-3 and also skills presents in Basic Competence KI-4 of learning precision. Implementation of KKP Ki-3 and Basic Competence KI-4 expected it will develop various behaviors that are reflection of KI-1 and KI-2. Through the comprehension concept and skills entirely, it will help the students to solve the problems that they faced in their daily life.

\section{ASSESSMENT SYSTEM OF CURRICULUM} 2013

Assessment system is almost two years worked. However, in implementation of it still needs to repair and also needs to socialize deeply to the all of education elements. One of them is assessment system of curriculum 2013. Assessment system of curriculum 2013 has differences if it compared with School Based Curriculum. Therefore, the government attempts to give image in assessment system of curriculum 2013. Also read: elementary school report application of curriculum 2013. Assessment can be called as a collecting process and processing information for measuring of attainment learning result of students (regulation of ministry education and culture number 66 in 2013). Assessment is sequence of activity for obtaining, analysis, and interpretation data about process and learning result of the students that implemented systematically and continuously, so that, it becomes to comprehend information in taking a decision. Assessment can be done during in learning activity (assessment process) and after the learning end (result/product assessment).

\section{Principle and Approaching Assessment}

Principles have to be noticed by teacher in doing assessment for implementation of curriculum 2013 are follows: (1) valid, it means assessment based on the data that reflecting the competence which want to measure; (2) oobjective, assessment based on the procedure and clear criterion and it is not influenced by subjective of assessor; (3) fair, an assessment has not advantage and disadvantage student because they have differences of religion background, ethnic group, culture, custom, social and economic status, and gender, and have specialty; (4) integrated, assessment said that it can fulfill this principle if teacher is a component not separated from learning activity; (5) transparent, where criterion of assessment and basic of taking decision that used can be known by all of authoritative side; (6) systematic, assessment has done by teacher; it must be planned and implemented step by step by using standard of stages; (7) accountable, process and the result of assessment can be responsible, either technically, procedure, or the result; and (8) educative, assessment conducted for importance and progression of student education.

\section{CONCLUSION}

Assessment approaching that used is Referenced Criterion Assessment. It is assessment competence attainment which based on minimum criteria of mastery learning (Kriteria Ketuntasan Minimal / KKM). Minimum Criteria of mastery learning are minimum criteria of mastery learning that determining by education unit with considering of characteristic of basic competence that will be achieved, support energy, and characteristic of student. That was called that standard assessment in Curriculum 2013 is more emphasizing in honesty principles; it sets out of aspect such as knowledge, skill, and attitude. One of these forms is authentic assessment. Authentic assessment called in curriculum 2013 is assessment model that implemented in directed learning based on three components above. Between technique and instrument assessment in Curriculum 2013 as follows:

1. Behavior competence assessment. Teacher does the behavior competence assessment through observation, self assessment, peers evaluation, by the student and journal. The instrument for observation, self assessment, and peers evaluation is checking list or rating scale with rubric, although in journal is teacher note.

2. Knowledge competence assessment, to assess the knowledge competence through the written test, oral test, and assignment.

3. Skill competence assessment, teacher evaluates skill competence through work evaluation, it is assessment to demand the student to demonstration a competence by using practice test, project, and portfolio assessment. The instrument is checking list or rating scale that completed by rubric. 


\section{REFERENCES}

[1] Hasan, S. H. 2015. Basic Material Policy and Curriculum Development of Basic Education. Tangerang: Open University.

[2] Ministry of Education and Culture. 2013. Basic Laws: Implementation of Curriculum 2013 Elementary School. Jakarta: Directorate General Primary Education and Directorate Construction of Primary Education.

[3] Ministry of Education and Culture. 2013. Guidance of Character Education Development through Extracurricular in Elementary School. Jakarta: Directorate General Primary Education and Directorate Construction of Primary Education

[4] Ministry of Education and Culture. 2013. Guidance of Character Education Development through Role And Society In Elementary School. Jakarta: Directorate General Primary Education and Directorate Construction of Primary Education

[5] Ministry of Education and Culture. 2013. Laws No. 20 in 2013 About National Education System. Jakarta: Ministry Of Education and Culture.

[6] Ministry of Education and Culture. 2013. Regulation of Ministry Of Education and Culture No. 54 in 2013 about Standard Graduate Competence. Jakarta: Ministry Of Education and Culture.

[7] Ministry of Education and Culture. 2013. Regulation of Ministry of Education and Culture No. 65 in 2013 about Standard Process. Jakarta: Ministry Of Education and Culture.

[8] Ministry of Education and Culture. 2013. Regulation of Ministry of Education and Culture No. 66 in 2013 about Standard Evaluation. Jakarta: Ministry Of Education and Culture.

[9] Ministry of Education and Culture. 2013. Regulation of Ministry of Education and Culture No. 65 in 2013 about Standard Process of Basic Education And Junior High School. Jakarta: Ministry Of Education and Culture.

[10] Ministry of Education and Culture. 2013. Regulation of Ministry of Education and Culture No. 81 A in 2013 Enclosure IV about General Manual of Learning Process Consist of Five Main Learning Experience are Observation, Asking, Collecting Information/Experiment, Associating and Communicating. Jakarta: Ministry Of Education and Culture.

[11] Ministry of Education and Culture. 2013. Regulation of Ministry of Education and Culture No. 32 In 2013 about Change of Government Regulation No. 19 in 2015 about National Standard Education. Jakarta: Ministry Of Education and Culture.

[12] Ministry of Education and Culture. 2013. Regulation of Ministry of Education and Culture No. 68 in 2013 about Basic Frame and Curriculum Structure of Junior High School and Islamic Junior High School. Jakarta: Ministry Of Education and Culture.

[13] Ministry of Education and Culture. 2013. Technical Guidance: Compiling Planning of Learning Implementation in Elementary School. Jakarta: Directorate Construction of Primary Education.

[14] Ministry of Education and Culture. 2013. Technical Guidance: Learning Fused Theme With Scientific Approaching in Elementary School. Jakarta: Directorate Construction of Primary Education.

[15] Ministry of Education and Culture. 2013. Technique Guidance: Evaluation in Elementary School. Jakarta: Directorate General Primary Education and Directorate Construction of Primary Education.
[16] Ministry of Education and Culture. Integrated Thematic Learning Applied in Elementary School in Curriculum 2013. Jakarta: Ministry Of Education and Culture. 